\title{
Material Speculation: Actual Artifacts for Critical Inquiry
}

\author{
Ron Wakkary ${ }^{1,2}$, William Odom ${ }^{1}$, Sabrina Hauser ${ }^{1}$, Garnet Hertz $^{3}$, Henry Lin ${ }^{1}$, \\ Simon Fraser University, Surrey, British Columbia, Canada ${ }^{1}$ \\ Eindhoven University of Technology, Eindhoven, Netherlands ${ }^{2}$ \\ Emily Carr University of Art and Design, Vancouver, British Columbia, Canada ${ }^{3}$ \\ \{rwakkary, wodom, shauser, hwlin\}@sfu.ca; r.l.wakkary@tue.nl; ghertz@ecuad.ca
}

\begin{abstract}
Speculative and fictional approaches have long been implemented in human-computer interaction and design techniques through scenarios, prototypes, forecasting, and envisionments. Recently, speculative and critical design approaches have reflectively explored and questioned possible, and preferable futures in HCI research. We propose a complementary concept - material speculation that utilizes actual and situated design artifacts in the everyday as a site of critical inquiry. We see the literary theory of possible worlds and the related concept of the counterfactual as informative to this work. We present five examples of interaction design artifacts that can be viewed as material speculations. We conclude with a discussion of characteristics of material speculations and their implications for future design-oriented research.
\end{abstract}

\section{Author Keywords \\ Material Speculation, Speculative Design; Design Fiction. Critical Inquiry}

\section{ACM Classification Keywords}

H.5.m. Information interfaces and presentation (e.g., HCI): Miscellaneous.

\section{INTRODUCTION}

Interaction design and human-computer interaction (HCI) have long borrowed from fiction in design techniques like scenarios, personas, enactments, and even prototyping. Speculative inquiries in design like futuring, forecasting, and envisionments have also deeply incorporated practices of fiction. Recently, design fiction has emerged as a uniquely productive approach to speculative inquiries. Most importantly, design fiction has extended the speculative aim of design-its future orientation-into more reflective realms that critically challenges assumptions we hold about design and technology. This is a valuable step in interaction design research toward offering approaches to more critical speculative inquiries.

Copyright $\subset 2015$ is held by the author(s). Publication rights licensed to Aarhus University and ACM

5th Decennial Aarhus Conference on Critical Alternatives August 17 -21, 2015, Aarhus Denmark

DOI: http://dx.doi.org/10.7146/aahcc.v1i1.21299
In considering the productive pairing of design and fiction to advance critical speculation, there is an opportunity to explore other forms of fiction informed practices that might nurture and expand interaction design research efforts. To date, fictional thinking in design has focused on science fiction and scenarios, and on conceptual artifacts like nonfunctioning prototypes, storytelling props, and fictional objects. The HCI community has paid less attention to other theories of fiction in addition to science fiction. Relatedly, HCI researchers have largely overlooked the role that actual and situated artifacts in the everyday can offer for speculative and critical inquiries in design. This shift in attention to actual and situated artifacts would reveal design artifacts and everyday settings to be sites for speculative and critical inquiry.

This paper introduces a complementary concept to design fiction that we call material speculation. This concept draws on the literary theory of possible worlds [cf. 48]. Material speculation emphasizes the material or mediating experience of specially designed artifacts in our everyday world by creating or reading what we refer to as counterfactual artifacts. Material speculation utilizes physical design artifacts to generate possibilities to reason upon. We offer material speculation as an approach to critical inquiries in design research. In plain fashion, for this paper we consider speculative inquiries that aim to generate progressive alternatives to be critical inquiries.

Our work builds on speculative and critical design, which can be seen as broad yet established approaches to design aimed at exploring and questioning possible, plausible, probable, and preferable futures [18, 19, 24]. Notions of speculative and critical approaches to design have a long history that extends across several disciplines and continue to be the subject of ongoing theorization and debate $[4,18$, $41,30,1,50,27]$. A primary goal of this paper is to contribute to the growing relevance and interest in a speculative and critical position on design in the $\mathrm{HCI}$ community. We do this through proposing material speculation as a conceptual framing for reading and creating design artifacts for critical inquiry. It is important to note that we do not propose material speculation as a means of classification or definition of artifact types or design approaches. In this sense, aspects of material speculation may well overlap with design fiction, or related notions like speculative design or critical design. Our aim is 
not to develop a mutually exclusive term or to create a hierarchy among concepts. However, we believe there are unique benefits and outcomes in using the conceptual framing of material speculation to understand design artifacts and to create them.

Our contributions in this paper are multi-fold. We extend the critical and reflective speculation in interaction design and HCI research by articulating the concept of material speculation. This concept advances the notion that the material existence of specifically designed artifacts situated in the everyday represent a unique and productive approach to critical inquiry. This paper also contributes a theorized understanding of material speculation and, by extension, fiction-focused practices in design research through the reasoned adaption of possible worlds theory to interaction design research. More broadly, the paper can be seen as another step forward in supporting the need for more reflective and critical forms of knowledge production in HCI and interaction design. Importantly, we stress that this type of critical inquiry occurs through the conceptualizing and crafting of design artifacts to generate theoretical articulations and intellectual argumentation.

\section{BACKGROUND AND RELATED WORK}

The review of related work that follows is intended to establish two main points: 1) the potential of critical speculation in design, 2) the crafting and material strategies in speculative inquiries in design that serve as antecedents and inspirations for material speculation.

\section{Speculation and fiction in design}

Fiction has had a long trajectory of use in interaction design research, particularly as a means to aid the process of interaction design and more recently as a mode of critical inquiry. Design as a discipline is concerned with change and preferred futures. As a result there is a natural orientation towards the future and the use of futuring activities in design. For example, the creation of personas fictional characters representing potential users - [15] and scenarios - narrated descriptions of future design details to inform design rationales - [14]. In parallel, prototyping has been a useful technique in design leading to final (future) designs through mockups and models. These practices of design can be seen to draw on fictional thinking or include fictional components. In design fiction, the use of fictional practices in design becomes more explicit and a source for investigating the speculative potential of design.

Design fictions relate to representations of the future from science fiction to design scenarios that detail "people, practice and technology" [8, p.133]. Discussions on technological futures have been well established within Science and Technology Studies (STS) [13, 52, 43], yet these discussions are relatively new to interaction design and HCI. The term design fiction arose in a presentation given by Julian Bleecker in 2008 [9]. Bleecker sees in the idea of science fiction a genre-methodology for design [9]:
"Design Fiction is making things that tell stories. It's like science-fiction in that the stories bring into focus certain matters-of-concern, such as how life is lived, questioning how technology is used and its implications, speculating about the course of events; all of the unique abilities of science-fiction to incite imagination-filling conversations about alternative futures."

For Dourish and Bell [17], science fiction provides a representation of a practice in which technical and material developments will be understood. It is not only that science fiction stories offer imaginary prototypes of things to be but also that science fiction creates environments in which these things are discussed, understood, and used. The fictional embedding of design and technology with fictional people and in practices brings to the fore the cultural questions of these futures and the roles of technologies. Dourish and Bell [17] argue that these cultural issues are inherent in our notions of design and technology. Science fiction reveals our prior cultural commitments before any implementation of design or technology. What emerges in their readings of science fiction is an "imaginative and speculative figuring of a world" in which new things and technologies will inhabit; and the bringing into focus of the "central role of sociological and cultural considerations" that are often obscured in our techno-centric reasoning of actual technologies [17]. What is evident is that science fiction affords an enhanced form of critical reasoning on technologies and design.

Similarly, Reeves [42] sees design fictions as texts to be productively read and unpacked. Reeves argues a greater role should be given to fiction in the futuring activities of design that he refers to as envisioning. In his view, a more critical envisioning would disentangle the aspects of fiction from the less productive qualities of forecasting and extrapolations [42, p.1580] (see [10] as an exemplary approach to envisioning through fiction). Reeves specifically cites Bleecker's method of design fiction that sets out the goals of not only reading but generating design fictions that express multiple futures and by that let go or challenge assumptions about the direction and breadth of progress. Bleecker and Reeves see in design fictions a design method that engages assumptions of the future as a means to derive critical understandings of the present.

Similarly, Bardzell and Bardzel [3] see how fiction and science fiction can reinvigorate visioning in HCI through what they conceptualize as cognitive speculation. ${ }^{1}$ They propose a form of speculative thinking that is grounded in the realities of current science but rely on imaginative extrapolation that is intellectually rigorous and reasoned. This methodological approach mobilizes science fiction to

\footnotetext{
${ }^{1}$ It should be noted that our use of the name "material speculation" is largely coincidental to the name of Bardzell and Bardzell's concept.
} 
critically inquire and envision technological futures that foreground the lived experiences of the future world.

These deeply articulated discussions help to reveal the significance and potential of science fiction in design and critical inquiry. In essence, the practices of science fiction bring to design research the reasoning on multiple futures that challenge assumptions and the sociological, cultural, and political tendencies that underlies our representations and considerations of design and technology.

In considering a design orientation to critical inquiry, cognitive speculation can be seen to have higher-level concerns that run parallel to our comparatively grounded concerns with material speculation. With respect to design fiction, its limitation is its emphasis on the creation or reading of fictional texts that are embedded with references to design and technologies. The artifact in design fictions is a mere reference, prop, or non-functioning prototype referred to as a diegetic prototype based on Kirby [29]. To paraphrase Kirby, a diegetic prototype is a technology or technological artifact that only exists in the fictional world but fully functions in that world. In opposition to that, our discussion of material speculation opens the critical functioning of alternative futures in design through the crafting of material artifacts that operate and exist in the actual world. This shift to materialized and crafted speculations draws on the work we generally refer to as speculative design.

\section{Crafting material speculations}

Speculative artifacts have played important and ongoing roles in design-oriented research in and outside of HCI. For example, Sengers and Gaver [49] unpack a range of speculative design artifacts that critically inquire into-and often complicate or unsettle-the relationship between functionality and user interpretation in interactive systems design. While these design artifacts were diverse and targeted various contexts, they are united in their aim to speculatively open up situations that subvert a single authoritative interpretation of a system in the service of provoking people to arrive at their own self-determined understanding of the meaning and 'use' of a system. Across these cases, ambiguity is leveraged as a resource to create embodied, functional systems to provoke dynamic, varied, and speculative interpretations of the design artifacts from the perspective of the user.

Dunne's earlier notion of para-functionality [20] predates the related work of Sengers and Gaver [49], where speculative design artifacts are intentionally crafted to encourage reflection on how technological devices and systems shape (and often constrain) people's everyday lives, behaviors, and actions in the world. In articulating para-functionality, Dunne draws on a wide range of examples from furniture exhibitions to radical architecture proposals to satirical design projects to unpack how design artifacts can construct social fictions that critically speculate on industrial progress and consumer culture, and on the nature of design itself in these contexts. Dunne makes clear that the 'functionality' of these design artifacts is to act as materialized props through which alternative stories emerge that operate in the space between rationality and reality, where "people can participate in the story, exploring the boundaries between what is and what might be" [20, p. 67]. In other words, through leveraging the seductive language of design, design artifacts are crafted to provoke people to imagine it in use and the possible future that would manifest around it - to "become lost in a space between desire and determinism" [20, p. 67].

Dunne and Raby [18] develop this strategy further through their notion of physical fictions (p. 89), where design artifacts extend beyond being merely props for films never made, to being situated as things in exhibition spaces that "prescribe imaginings" and "generate fictional truths" (see p. 90). The aim of physical fiction design artifacts is to critically project different possibilities and to "challenge the ideas, values, and beliefs of our society embodied in material culture" (p. 90). Similar to Sengers and Gaver's [49] aim to shift the site of meaning-making from the maker to the user, physical fictions aim to open up moments of suspended belief and, in doing so, shift our role from user to imaginer. However, similar to para-functional objects these are discursive objects - crafted interventions to create discussions. Dunne and Raby [18] refer to these as "intentional fictional objects" with no aim to be real: "physical fictions that celebrate and enjoy their status with little desire to become 'real'" (p.89). For Dunne and Raby, the ideal dissemination for their research and experimentations is in the form of exhibitions in museums and galleries, which "function as spaces for critical reflection" [18, p. 140].

Designers Auger and Loizeau (see www.augerloizeau.com) create speculative design projects that, similar to Dunne and Raby, take the form of installations within galleries. Drawing on a range of projects from the Royal College of Art, Auger [2] offers insights into the crafting of speculation in design. Borrowing from a range of techniques in the humanities and sciences, Auger reflects on important dimensions surfaced from these speculative design projects - from generating tension to conflict with engrained systems in our familiar everyday ecologies to carefully managing the uncanniness of the design artifact to provoke viewers to engage with the issue(s) it speculates on. These dimensions are important for constructing what Auger calls the perceptual bridge: "In effect, a design speculation requires a bridge to exist between the audience's perception of their world and the fictional element of the concept" [2, p. 2].

The work discussed above reveals the role the materialized design artifact can play in critical inquiry and to shift the authority of the interpretation to the "imaginer" or "user". A further lesson is that the material forms, along with the 
concepts, mutually shape the inquiry and through this process become unique or specialized types of artifacts. In all cases the artifact serves as a bridge between our current world and an imagined critical alternative or transformed view of our world.

The intent and shaping in Dunne and Raby, and Auger and Loizeau are rhetorical strategies aimed at material artifacts as discursive interventions. As such, these designers situate their work in exhibitions arguing it occupies a critically reflective space between the real and the unreal. We argue through material speculation that the converse is equally insightful - that material speculations find a critical space of inquiry by occupying the actual or everyday world as opposed to a gallery space.

In relation to the open-ended and leveraging of ambiguity in design in the work of Sengers and Gaver [49], work like the Prayer Companion [23] serves as an antecedent to material speculation. Through crafting and situating a very particular material and functional form in the everyday world it speculates and reasons in a highly critical fashion.

The use of science fiction design has extended it into realms of critical inquiry that have productively opened new territory. Design fiction makes explicit the potential of fiction in combination with design to challenge and reconsider assumptions and underlying issues in order to more critically and reflectively consider next steps and advances in design and technology. Moving beyond fictional texts that embed references to design and technologies, crafted speculations are equally critical and have the capacity and dexterity to tackle broad topics for inquiry that may reflect back on design or focus beyond the field. Crafted speculations reveal the potential of shifting interpretation and meaning making to users and audiences of design through an openness and provocation embodied in the design artifacts. In the next section, we begin our descriptions of material speculation and how it contributes to this body of work.

\section{MATERIAL SPECULATION}

In what follows, we begin with an introduction of the literary theory of possible worlds. We follow this with a description of five examples of interaction design artifacts that can be viewed as material speculations. Lastly, we describe and interpret characteristics of a material speculation.

\section{Manifestations of possible worlds}

Here we articulate how particular design artifacts can be seen to generate possible worlds. We draw on key concepts from possible worlds theory to support our idea of material speculation. These include the notion of actual versus possible worlds and the notion of the counterfactual. We discuss how design artifacts can be seen as counterfactual artifacts while still being material things. We argue that the material actuality of counterfactual artifacts enables them to advantageously occupy a creative space at the boundary between actual and possible worlds. We also elaborate on how counterfactual artifacts generate possible worlds through encounters with people. As a consequence of these features, material speculation acts as a form of critical inquiry.

\section{Possible worlds theory}

Possible worlds is a philosophical concept developed in the latter twentieth century by the analytical school, including philosophers Saul Kripke and David Lewis [34, 48] and was later adopted by literary theorists [cf. 38, 22, 45]. Philosophically, possible worlds is an approach to the problem of counterfactual statements in modal logic. For example, Kripke asks what is the truth condition of the statement that Sherlock Holmes "does not exist, but in other states of affairs he would have existed" [31]; or this counterfactual statement by Ryan [48], "if a couple hundred more Florida voters had voted for Gore in 2000, the Iraq war would not have happened." In modal logic, the question is how is each of these counterfactual statements interpreted to be true or false. The philosopher David Lewis who bridged analytical philosophy to literary theory [32] offered the position that propositions like counterfactual statements can be seen to be either true or false dependent on in which worlds the statement is true and which worlds the statement is false [34]. This allows for a reasoned argument to be made on the inevitability of the Iraq war if Al Gore was indeed elected president in 2000 despite the fact that he was not elected president. This allows for the fictional world of Sherlock Holmes to unfold such that any faltering of the detective's deductive reasoning would be perceived as false or a negative development in the character's intellect.

Counterfactuals are central to the theory of possible worlds. By virtue of contradicting one world (e.g., the world in which Al Gore lost the presidential election), they elicit and open up another possible world (e.g., a world in which Al Gore won the presidential election). Lewis describes counterfactuals as similar to if...then operators that create conditional modes in which possible worlds may exist [32, 48].

Possible worlds theory relies upon the ideal that reality is comprised of all that we can imagine and that it is composed of the "actual world" and all "possible worlds" [47]. Philosophically, there are different approaches to this idea however Lewis' view tends to prevail and is most influential with respect to literary theory [47]. Lewis sees the actual world as the concrete physical universe over time. In most respects, possible worlds are materially similar to the actual world, however they are not connected in any way spatially or temporally [33]. Importantly, Lewis also views actual worlds as having no privilege over possible worlds, rather actual worlds are simply our world, the one we inhabit. The actual world is indexical. It merely refers to the world of the inhabitant or the one who is 
speaking within a given world. In this sense, all worlds like the actual world hold their own internal logic and autonomy.

\section{Metaphorical transference of possible worlds to interaction design in material speculation}

Amongst literary theorists there is the question of the legitimacy of considering fictional worlds as possible worlds [e.g. 44]: Would analytical philosophers validate the idea of fictional worlds as possible worlds? Ryan is equally content with the notion of a metaphorical transference between disciplines [48]. She cites fellow theorists Lubomír Doležel to argue that even if considered a metaphorical transference, the validity of the application of possible worlds theory is its potential to identify unique features of fiction that other approaches do not [48]. It is in this spirit that we extend possible worlds theory to interaction design and $\mathrm{HCI}$.

Material speculation is the adaption of possible worlds theory to design research. As we have discussed, when considering possible worlds and counterfactuals, in philosophy or fiction we are concerned with either a statement of logic or a text. In design, we are concerned with a material thing. A counterfactual is a virtual or tangible artifact or system in design and HCI rather than statement or text. Hence we refer to it as a counterfactual artifact. The notion of an actual counterfactual is a departure from Lewis' criterion that possible worlds have no spatial or temporal connections to the actual worldthey are remote. Yet, here we view this departure more advantageously than negatively.

\section{The creative boundary between the actual and the possible}

There is a productive and creative space at the boundary between the actual and possible worlds, or the real and the fictional. There are many examples from fiction in literary texts, theatre or film where authors intentionally blur the distinction between actual and possible worlds for its creative possibilities. Whole genres have emerged like mystery or interactive dinner theatres that directly involve audiences in the fictional world. Live action role-playing games, augmented reality games or alternate reality games actively transgress the boundary between the real and fictional. Janet Murray's notion of the "fourth wall" in interactive media aimed to cross theatrical illusion and actuality [35]. In these cases, interactivity is the counterfactual action that crosses the divide: fictional characters are not supposed to interact with actual people or in the actual world. In material speculation, it is making the counterfactual into an actual artifact that crosses the divide between the actual and possible worlds since, as we discussed earlier (see Possible worlds theory), counterfactuals are not supposed to exist in the same time or place as the actual world.

Ryan [48] referred to this potential in her principle of minimal departure in which she argues that in the case of fiction a reader construes a possible world to conform as much as possible to his or her actual world. In other words, the reader departs from his or her perceived reality only when necessary. The obvious benefit for fictional authors is that there need be no accounting for the rising and setting of the sun; if its not described in the text, a reader can assume the daily rotation of the planet. In addition, critical differences can be focused upon such as in a reference to a winged horse - a reader can imagine the combination of a known horse with known wings and speculate on that difference between the possible and the actual. These aspects give a critical functioning to the boundary between the actual and the possible. Truth conditions of the possible are seen to be relevant to the actual or at least open to be speculated upon. Further, there is a set of relational propositions that are automatically considered such as: What kind of saddle might a winged horse have? Where do flying horses migrate and settle? Is there a whole new biological class between the classes of mammals and birds? The theorist Thomas Pavel [38] referred to this as the adoption of a new ontological perspective that gives possible worlds a degree of autonomy.

Given that counterfactual artifacts sit on the actual side of the boundary between the actual and possible worlds this sense of a new ontological perspective is arguably more pressing. An actual counterfactual artifact not only opens up speculation on the artifact but on its conditions as well. When encountering a material speculation, potential reasoning would include not only 'what is this artifact' but also 'what are the conditions for its existence' (e.g., including the systemic, infrastructural, behavioral, ideological, political, economic, and moral). Material speculation probes the desirability of the truth condition of the proposition and the conditions bound to it.

The counterfactual artifact as proposition and generation of possible worlds

In material speculation we can see the counterfactual artifact as embodied propositions similar to propositions in counterfactual statements in analytical philosophy. It is helpful to think of the counterfactual artifacts as being if...then statements as we discussed earlier (see Possible worlds theory). In this sense, the counterfactual artifacts trigger possible world reasoning that extends beyond them. In other words, the possible world or fictional account is not embodied fully in the counterfactual artifact rather it is generated by interactors in the encounter or experience of the counterfactual artifact. It is not a limitation that the counterfactual artifact is of our actual world, rather it is this very actuality that provokes or catalyzes speculation by being at the boundary of the actual and the possible.

In fiction, the discussion of where the possible world is situated is more complex. Since the influence of poststructuralist thinking on literary theory, namely in concepts of open work by Umberto Eco [21] and textuality by Roland Barthes [7], meaning and fiction are seen to be 
generated in the act of reading by readers and not solely by the author. The importance of this for material speculation is that those interpreting or reasoning upon the counterfactual artifacts also generate possible worlds in multiplicity. Eco viewed a literary text as "a machine for producing possible worlds" [21, p.246] and in this sense we view a counterfactual artifact as a "machine" for producing possible worlds.

\section{The transference of criticality to interaction design}

The adaption of possible worlds gives fiction an immense criticality. Fictional texts can speculatively yet critically inquire upon our world. As Ryan argues [48], fiction has the capacity of truth and falsity giving it more consequence than when perceived as artistic lies or fantasy. Fiction assumes a real world shared between actual and possible worlds giving it a perch for relevance and critical insights into our actual world. However, through counterfactuals, it does not mimic the actual world, rather readers and authors alike construct possible worlds different than the actual world leading to creative and reasoned speculations [48]. In interaction design, counterfactual artifacts can also be seen to gain a perch in this critical inquiry space of consequential propositions rather than matters of functionality or consumption.

The critical nature afforded to fiction with recourse to possible worlds is that its embodied propositions can be accepted as truthful under certain conditions. With respect to the actual world, or our world, the choice can be to regard the propositions as false under the conditions of our actual world. Or it can be seen as a critical alternative, which is to change the conditions of our actual world to make the proposition truthful. This, in essence, is the model for material speculations in interaction design research as a mode of critical inquiry.

\section{Summary}

In summary, we can see how possible worlds theory, enabled by the work of literary theories, can be applied to interaction design research to develop the notion of material speculation. The basic outlines of material speculation can be summarized as the manifestation of a counterfactual in a material artifact that we refer to as a counterfactual artifact. As a material thing it occupies the boundary between actual and possible worlds. The counterfactual artifact is also an embodied proposition that, when encountered, generates possible world accounts to reason on its existence. These two aspects combined afford material speculations a position in critically speculating on the actual world.

\section{Examples of material speculation}

In what follows we provide an overview of examples of interaction design artifacts that can be read as material speculations. We aim to emphasize their actual material existence situated in everyday settings. With our examples, we focus largely on the description of the design artifacts as our aim is to illustrate how they exemplify counterfactual artifacts. We only hint at the multitude of possible worlds each may generate since this is part of the lived experiences of each example. Our accounts of possible lived worlds of these material speculations are not intended to be exhaustive since this would require a separate and more indepth treatment of each that is beyond the aims of this paper.

Inaccessible Digital Camera [40]_The inaccessible digital camera is a digital camera that is made of concrete; all photos are stored locally inside of its concrete case. The only way for the owner to view the photos stored on the camera is to, in effect, break the camera and retrieve the memory card stored inside (see figure 1). The inaccessible camera is part of a larger set of 'counterfunctional devices' designed to explore how enforcing limitations in the design of interactive technologies can potentially open up new engaging possibilities and encounters. In a later project [39], elements of the inaccessible camera design were embodied in another counterfunctional camera, named the Obscura 1C, which again had a form comprised of cement that required its owner to break it to access the digital photos stored on a memory card inside. Participants were exposed to the capsule camera in a lab setting and, later in a different study, the Obscura 1C was handed out or sold to people via an online website (e.g., Craigslist.com).

The inaccessible camera can be seen as counterfactual in that it draws its owner into a familiar device and interaction-taking a photo with a camera. However, its form and composition depart into an alternative situation in which one must destroy the digital device recording one's life experiences in order to access these digital records. In our contemporary world of constant availability and connectedness, these counterfunctional cameras project a critical stance on 'functionality' — one based on inhibiting, restricting or removing common or expected features of a technology. To initiate consumption of one's digital photographs, one must first encounter the discomfort of destruction. On a broader level, encounters with the inaccessible camera invite critical reflection on one's own practices contributing to unchecked digital content production and the almost unnoticed or assumed eventual obsolescence and disposal of everyday digital devices.

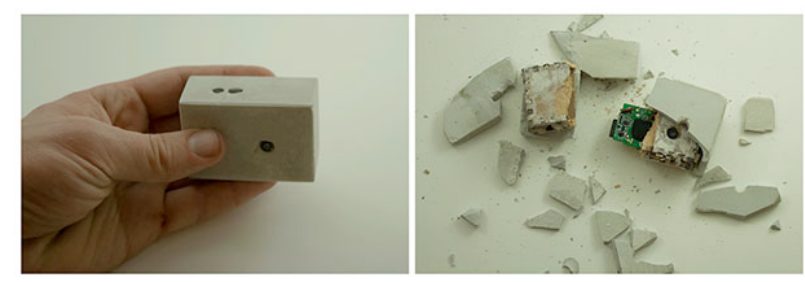

Figure 1. The Inaccessible Digital Camera [40]. 
Rudiment \#1 [26] - Rudiment \#1 is a small machine encased in wood and plastics that affixes magnetically to surfaces, such as a refrigerator door (see figure 2). This machine consists of two main parts or 'modules' that are connected by a flexible cable. One part moves across a magnetic surface with magnetic wheels when it's narrowrange infrared detector senses peripheral movement. The speed and direction are also randomly changed each time these sensors detect close by movement. The second part is wired to the first part; it provides the first module with power and also signals further movement when its own wide-range infrared detector senses movement. Both parts are able to detect when an edge or obstacle is reached and are programmed to change direction if either are encountered. The authors' aims for designing Rudiment \#1 (and also its cousins Rudiment \#2 and \#3) were to speculatively explore how interactive machines might exhibit autonomy, and how this might be interpreted and speculated on by people living with them. Two households in the southeast region of the United Kingdom experienced rudiment \#1 for roughly four weeks each.

From the beginning household members struggled to make sense of Rudiment \#1 when they encountered it. Interactive technologies and machines commonly occupy our everyday environments, but the combination of an unclear 'function' or purpose paired with unfamiliar, yet resolved aesthetics prompted a range of speculations on what Rudiment \#1 is and the nature of its intelligence and autonomy. These design qualities provoked and challenged household members to encounter a world in which machines may exhibit and enact a form of autonomy that is very different from what we know and understand in our world today. This was evident in household members' initial use of 'pet' metaphors in attempts to describe their relations to the Rudiments. However, participants eventually migrated to focus on qualities of function and engagement to make sense of the autonomy exhibited by the Rudiments. In one case household members perceived that Rudiment \#1 could be networked to other machines within their home, and in other cases ongoing encounters with the Rudiments led

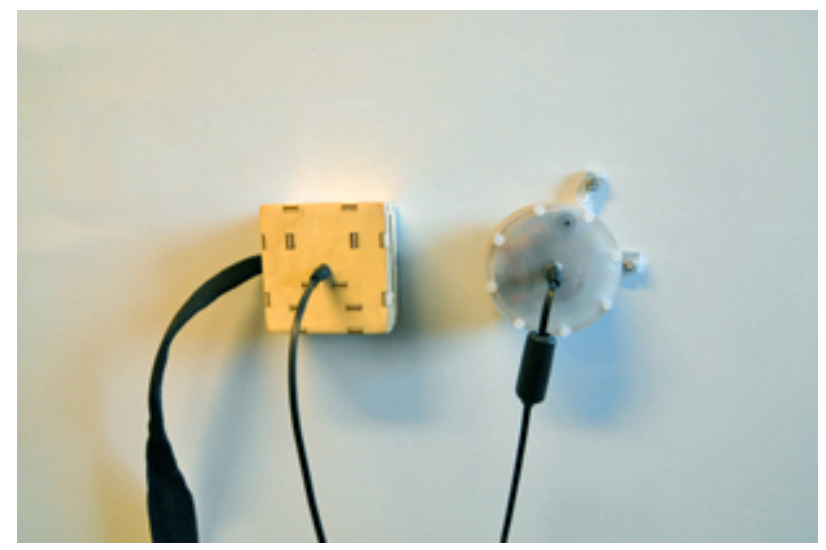

Figure 2. Rudiment \#1 vertically affixed to a surface [26].

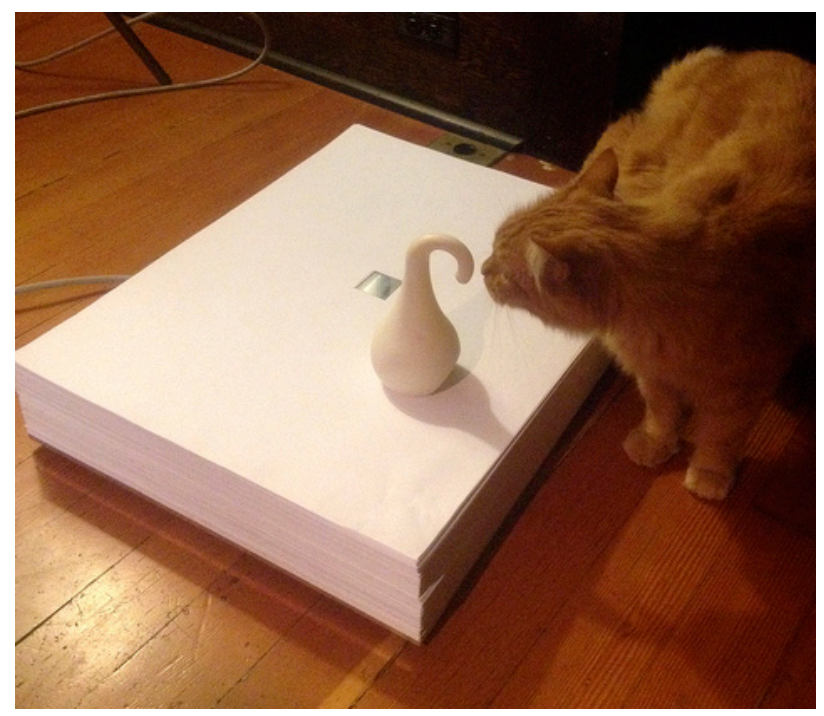

Figure 3. The table-non-table [54].

participants to more broadly consider their relationships to other machines and objects in the home. The Rudiments effectively struck the balance between offering relatively familiar materials and formal aesthetics, while operating in unfamiliar ways that opened up new possibilities for thinking about human relations to everyday computational things. Rudiment \#1 itself, along with the speculations triggered by household members' lived-with encounters, helped develop and advance a speculative space for moving beyond the design of "machines for our own good, to a possibility of interactive machines that might exhibit autonomy, but not as we know it" [26, p. 152].

Table-non-table [37, 54] - The table-non-table is a slowly moving stack of paper supported by a motorized aluminum chassis (see figure 3). The paper is common stock (similar to photocopy paper). Each sheet measures 17.5 inches by 22.5 inches with a square die cut in the middle to allow it to stack around a solid aluminum square post that holds the sheets in place. There are close to 1000 stacked sheets of paper per table-non-table, which rest on the chassis about one half-inch from the floor. The movement of the table is in short durations (5-12 seconds) that occur once during a longer period of time (a random selection between 20 to 110 minutes). The table-non-table lived with one household for five months, became part of two households for six and three weeks respectively, and became part of two households in a preliminary deployment for several days in Vancouver, British Columbia.

In some ways similar to Rudiment \#1, the table-non-table provoked a range of speculations as participants attempted to make sense of its purpose and place within their homes. While initially its owners attributed anthropomorphic qualities to the table-non-table (e.g., perceiving it had the abilities to 'hide' or 'pretend') [54], over time different 
relations emerged as encounters with it accumulated. The table-non-table became an artifact that was curiously computational and clearly required electricity, yet many of the ways participants used and related to it mirrored manipulations and reconfigurations more commonly associated with non-digital things. The flat surface of the table-non-table opened it up to being subtly drawn on, at times in unknowing ways as other objects were stacked on top and it slowly became just another thing in the background of domestic life. When its movement was noticed the owners often relocated it to different locations in the house or apartment as if trying to reveal different understandings of the artifact. In other cases, the subtle yet persistent movement of the table-non-table catalyzed emergent, creative interactions by people and their pets as a way of "resourcing" the table-non-table. For example, cats alternated between using it as a bed and viewing it as another entity with either caution or curiosity. In fact, one cat began to treat a heater appliance next to the table-nontable in a similar fashion as if similarly constituted objects were now alive. Both pets and people played with the sheets of paper from ripping them. People made drawings on the paper and turned them into large snowflakes [54]. The table-non-table can be seen as radically departing from how many people experience domestic technology on an everyday basis. In this way, people, pets and their material environments were reconfigured over and over again to try to incorporate the table-non-table alongside other domestic artifacts, spaces, and experiences over time.

Photobox [36]-The Photobox is a domestic technology embodied in the form of a well-worn antique chest that prints four or five randomly selected photos from the owner's Flickr collection at random intervals each month (see figure 4). The two main components of Photobox are an oak chest and a Bluetooth-enabled Polaroid Pogo printer (which makes $2 \times 3$ inch photos). All technological components are embedded in an upper panel in the chest in an effort to hide of 'technological' components from view. The printer is installed in an acrylic case that secured it to a

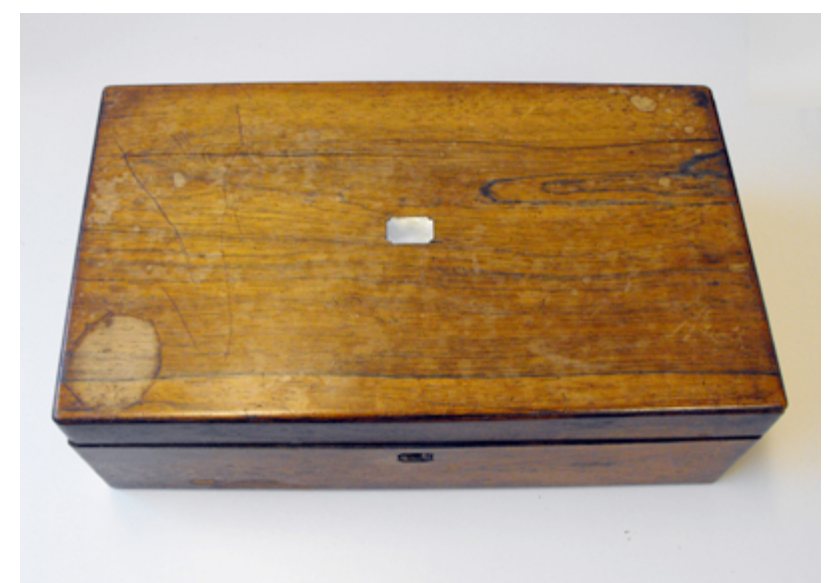

Figure 4. The photobox largely took the form of a European oak chest. [36] small opening in the panel to allow a photo to drop onto the central platform of the box. The Photobox's behavior is enacted through an application, which runs on a laptop that wirelessly connects to the embedded printer via Bluetooth. At the start of each month, Photobox indexes its owner's Flickr archive and randomly printed four or five photos that month. In similarly random fashion, it selects four (or five) photos and generates four (or five) timestamps that specify the print time and date for each photo; at print time, the matching photo was printed. The Photobox was created to speculatively explore how an interactive artifact could critically intervene in experiences of digital overload (i.e., the proliferation of digital photos) and, more generally, what might comprise a material instantiation of the slow technology design philosophy [25] — an interactive thing whose relationship with its owner could emerge and evolve over time. Three nearly identical Photoboxes were designed and implemented; three households in Pittsburgh, Pennsylvania, USA subsequently lived with a Photobox for fourteen months respectively.

The Photobox combines a recognizable form - a wooden chest - and a common experience-viewing and engaging with digital photos-within a networked design artifact that provoked both familiar and alien experiences across all households as they encountered this design artifact over time. The Photobox can be seen as counterfactual in that well-worn wooden chests do not manifest material rendering of one's online photo collection, at least in the world as we experience it today. Nonetheless, it was perfectly functional and developed a unique character and configuration within each of the three households that owned one. In addition to stimulating reflections from its owners about the memories it surfaced from deep within their digital photo archives, its unfamiliar (and uncontrollable) slow pacing paired with its classification among participants as 'a technology', triggered a range of reflections about participants relations to other technologies in the home and what values ought to constitute a domestic technology. The Photobox clearly departed from any kind of familiar combination of form, materials, and computational behavior that typically characterize domestic technologies. As a result, participants speculated on the nature of the artifact and technology in everyday life, though lived-with encounters over a long period of time. These encounters opened a productive space for framing future speculative design inquires.

Mediated Body [28] - Mediated Body is a symbiotic system consisting of a human ("the performer") wearing custombuilt technology ("the Suit"). The system offers a play session for a single participant (i.e. a person that is not the performer). The role of the technology is to sense physical bare-skin connection between the performer and the participant, where the sensing yields analogue values that range from a few centimeters from actual touch to light touch to full contact (see figure 5). The values are converted into a relatively complex soundscape, which is 
played back in the headphones that both the performer and the participant wear. Thus, from the participant's point of view, the performer is a musical instrument that she can play by touching. However, due to the design of the system, the instrument can also play its player: When the performer touches the participant, the soundscape is affected in the same way. The headphones make the interactive soundscape a shared experience between performer and participant, and they also serve to limit surrounding sounds and thus make the experience more intimate and private for the two players. Further, the suit includes bright lights on the performer's chest, which serve two purposes. First, the lights enhance the interactive properties of touch by changing color and pulse when a touch is sensed. Second, they broadcast some of the interaction dynamics of the ongoing session to the surrounding area. The mediated body was encountered at the week-long Burning Man Festival and in public spaces, such as the subway in Berlin (see Figure 5).

While different in many ways in terms of its materials, form and interactivity, the Mediated Body leverages familiar interactions (e.g., touching another human) to venture into unfamiliar territory similar to all of the prior examples. It was evident that encounters with the Mediated Body not only continually reconfigured relations between the performer and participant, but also the evolving social and material ecology encompassing these interactions. It generated encounters in which issues of social conformity became peripheral for the performer and participant in favor of direct, intimate engagements in public spaces. However, these engagements extended beyond the two people directly involved in the interaction as those around them also

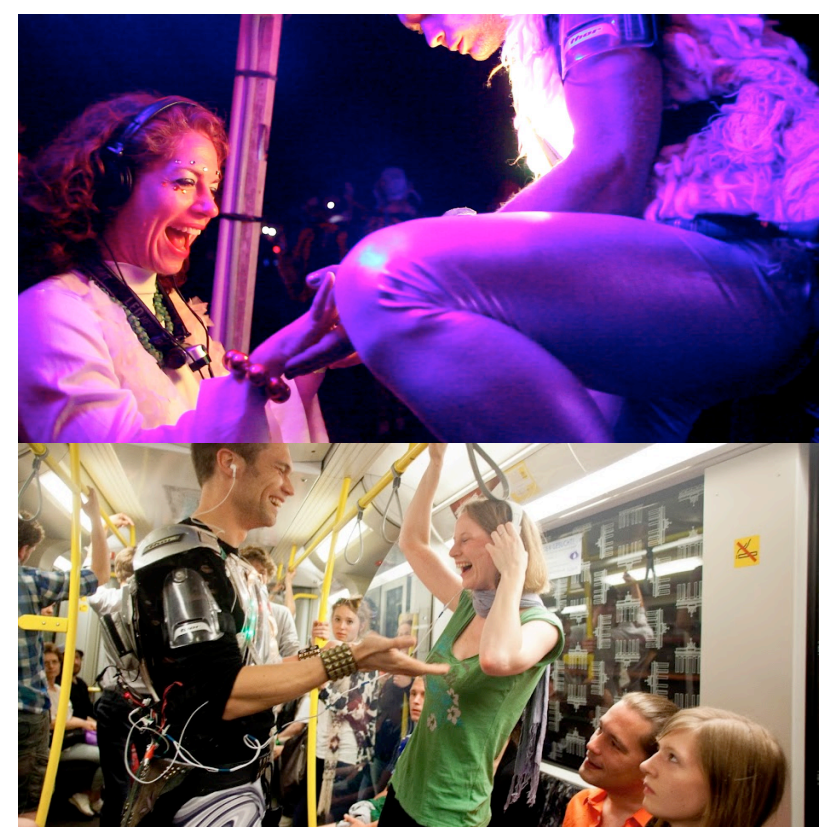

Figure 5. Top: Mediated Body [28] in use at the Burning Man festival. Bottom: The Mediated Body performed on a Berlin subway among many onlookers. engaged in making sense of this encounter in ways that differ considerably from the performer and participant (see Figure 5). The Mediated Body speculates on many issues pertaining to the mobile experience of new media, the cultivation and expression of personal space in public places, the human body as a technical interface, and the richness and tensions entangled across all of these themes.

\section{Characteristics of material speculation}

Based on the related works, adaption of possible worlds theory, and the accounts of material speculation examples, we summarize our conceptual framing with a series of characteristics.

Material speculation is the coupling of counterfactual artifacts and possible worlds-Material speculation is the sum of the counterfactual artifact that is designed to exist in the everyday world to be encountered and the multitude of possible worlds it generates by those encounters.

Counterfactual artifacts exist in the everyday world - The counterfactual nature of material speculations rely on the contradiction of the artifact not appearing to "fit the logic of things" in the everyday world yet undeniably existing in the actual world to be encountered. Counterfactual artifacts situated in the everydayness of our world offer a new ontological perspective that over time makes more visible assumptions, implications, and possible change. It is important for the depth and quality of the emergent possibilities that material speculations be a lived experience rather than simply an intellectual reflection. More diverse and deeper possibilities are generated through cohabitation, interactions, and constant encounters over time.

Counterfactual artifacts are generators of possible worlds-Counterfactual artifacts in material speculations do not embody possible worlds, rather they act as propositions that, if considered, generate lived-with engagements with new possibilities encapsulated within possible worlds. As we discussed earlier, counterfactual artifacts are machines that generate possible worlds. These include the world(s) as imagined by the designers, world(s) imagined by those who encounter the counterfactual artifact, and most speculatively, the counterfactual artifact itself can be understood to imagine a world.

Counterfactual artifacts are specially craftedCounterfactual artifacts in material speculations are specially designed artifacts. They are crafted with the intent and purpose to inquire on new possibilities. This is not a straightforward practice; it requires expertise and design judgment to create an artifact that successfully contradicts and deviates from the world around it, yet is entertained as a viable proposition in our everyday world. As evident across our examples, counterfactual artifacts are carefully shaped and designed through materials, form and computation such that the artifact is balanced between "falsely" existing in the actual world while being "true" in a possible world. 
Material speculation is critical inquiry-Counterfactual artifacts by nature challenge the actual world since they are designed to occupy the boundary between the actual and the possible. The criticality of a material speculation can arise from the quantity of possible worlds it opens up or the quality in which it suggests fewer possible worlds. In either case this speaks to the nature of the critical space revealed. The precision and promise of the critical inquiry is mediated through the crafting of the counterfactual artifact, which can be shaped and directed toward critical or needed spaces of inquiry.

\section{DISCUSSION}

In our discussion we review our contributions and the importance for $\mathrm{HCI}$ and interaction design research of the centrality of the actual and situated artifact. We also consider the potential future of speculative materiality as part of everyday practices.

\section{Actual and situated artifacts as knowledge}

A core goal of this paper is to complement the nascent and growing interest in design fiction in HCI and interaction design research through offering an alternative conceptual framing for critical and speculative inquiries in design. We aimed to expand on the criticality that design fiction brought to speculation in design research by motivating and developing the role that actual design artifacts can play in critical inquiries. Further, we sought to build on the traditions of craft and material work of speculative and critical design, as well as the shifting of responsibility for interpretation to users by including situatedness and lived with experience as sites for critical inquiry. A further contribution we made was to provide an in depth theoretical account to nurture the development of material speculation within HCI. We aimed to be as clear and transparent in our use of theory alongside the material speculation concept such that other researchers can not only refine and revise our concept, but also refine and revise our theoretical work, which may in turn lead to other insights.

On a disciplinary level, fundamental to the concept of material speculation is the centrality of the actual and situated artifact as a producer of knowledge in interaction design research. This articulation can be seen to support the increasing turn within interaction design and HCI research to develop forms of knowledge production centered on the essential role of designed artifacts. This advances the notion of making 'things' as a site of inquiry that produces insights, theories, and argumentation that is unique to interaction design research and distinct from critical art practice and the humanities $[5,51,30]$. We see our work as contributing to nascent and growing interest in design artifacts as generators of knowledge (e.g. annotated portfolios [12], critical making [41] and adversarial design [16], among others).

More broadly, our work parallels movements emerging outside of HCI and interaction design that critically advance the position that the things bare knowledge in distinct and complex ways. While there are important differences in their own epistemological commitments, emerging theoretical notions such as Bogost's [11] carpentryconstructing artifacts that do philosophy, where their real and lived existence embodies intellectual argumentationand Baird's [6] thing knowledge - artifacts can embody and carry knowledge prior to our ability to theorize or reason through language - offer intriguing perspectives that can be seen both as critical and generative mechanisms framing how we do and how we unpack approaches like material speculation within the interaction design community.

\section{Speculative materiality of everyday practices}

If critical speculative research in design shifts the emphasis of interpretation to the design audience or users, might we expect this same audience to go beyond interpretation and appropriation to the active engagement in crafting speculation themselves? Similar concerns have been explored previously in considerations of the intersection of social practices and design fiction. For example, Tanenbaum et al. [53] looked at the practice of Steampunk with the lens of design fiction. They discussed how Steampunk enthusiasts manifest both making and fictional practice that serves as an exemplar of the meeting of social practices and speculative inquiries through design. The authors argue that this intersection of fiction with materiality through making verges on making a possible world actual. Despite the impossibility of the Steampunk world becoming real it forms an ongoing social practice of non-designers centered on making such impossibility a reality. Wakkary et al. [55] explore the relation between speculation and material practices in a different manner. These authors describe how speculative inquiries in sustainable design like hydroponic kitchen gardens of the future or vertical gardens enabled a 'generative approach.' These speculations are taken up within the existing competences and materials of Green-DIY enthusiasts and realized today through, for example, Ikea-hacks for the hydroponic kitchen and reclaimed truck pallets turned into vertical gardens. Here, the meeting of the speculative and the material takes an everyday turn that is distinct but related to our discussion of material speculative inquiries for design-oriented research.

\section{CONCLUSION}

This paper has motivated and articulated material speculation as a conceptual framing to further support critical and speculative inquires within $\mathrm{HCI}$ and interaction design research. In this, we have reviewed and synthesized a theoretical account of possible worlds theory and the counterfactual, described and interpreted a set of examples of material speculations, and proposed characteristics of material speculations. Importantly our aim is to not be prescriptive nor conclusive, rather we intend to provide a conceptual framing to inspire future generative work at intersection of critical and speculative inquires targeted at 
the everyday in HCI. We concluded with actual and situated artifacts as knowledge and speculative materiality of everyday practices as opportunity areas for framing future contributions of material speculations in HCI and design. In our future work, we aim to refine and expand these concepts, both materially and theoretically. As the HCI community continues to seek out critical alternatives for exploring the nature of interactive technology in everyday life, we hope material speculation can be seen as a complementary framing for supporting these initiatives and, more broadly, the need to recognize and develop ways of practicing more reflective forms of knowledge production.

\section{ACKNOWLEDGMENTS}

The Social Sciences and Humanities Research Council of Canada (SSHRC), Natural Sciences and Engineering Research Council of Canada (NSERC), Banting Postdoctoral Fellowships, and Canada Research Chairs supported this research. We thank the many authors who gave us permission to reprint their work and images.

\section{REFERENCES}

1. Agre, P.E. 1997. Toward a critical technical practice: lessons learned in trying to reform AI. In Bridging the Great Divide: Social Science, Technical Systems, and Cooperative Work, Bowker, G. et al. (eds). Erlbaum, Mahwah, NJ, 131-157.

2. Auger, J. Speculative design: crafting the speculation. Digital Creativity, 24, 1 (2013), 11-35.

3. Bardzell, J. and Bardzell, S. A great and troubling beauty: cognitive speculation and ubiquitous computing. Personal and ubiquitous computing, 18, 4 (2014), 779-794.

4. Bardzell, J. and Bardzell, S. What is "critical" about critical design? In Proc. CHI 2013, ACM Press (2013), 3297-3306.

5. Bardzell, S., Bardzell, J., Forlizzi, J., Zimmerman, J. and Antanitis, J. Critical design and critical theory: the challenge of designing for provocation. In Proc. DIS 2012, ACM Press (2012), 288-297.

6. Baird, D. Thing Knowledge: A Philosophy of Scientific Instruments. University of California Press, Berkeley, CA, 2004.

7. Barthes, R. and Howard, R. S/Z: An Essay. Hill and Wang, New York, NY, 1975.

8. Bell, G., and Dourish, P. Yesterday's tomorrows: notes on ubiquitous computing's dominant vision. Personal and Ubiquitous Computing, 11, 2 (2007), 133-143.

9. Bleecker, J. Design fiction: A short essay on design, science, fact and fiction. 2009. Retrieved June 16, 2015 from http://blog.nearfuturelaboratory.com/2009/03/17/designfiction-a-short-essay-on-design-science-fact-and-fiction/
10. Blythe, M. Research through design fiction: narrative in real and imaginary abstracts. In Proc. CHI 2014, ACM Press (2014), 703-712.

11. Bogost, I. Alien Phenomenology, or What It's Like to Be a Thing. University of Minnesota Press, Minneapolis, MN, 2012.

12.Bowers, J. The Logic of Annotated Portfolios: Communicating the Value of 'Research Through Design.' In Proc. DIS 2012, ACM Press (2012), 68-77.

13. Brown, N., B. Rappert, and A. Webster (eds). Contested Futures: a sociology of prospective technoscience. Ashgate, Surrey, UK, 2000.

14.Carroll J. M. 1997. Scenario-based design. In Handbook of Human-Computer Interaction. Helander M., Landauer T.K., and Prabhu P. (eds). Elsevier, Amsterdam, NL, 383-406

15. Cooper, A. The inmates are running the asylum. Macmillan Publishing Company Inc., Indianapolis, IN, 1999 .

16.DiSalvo, C. Adversarial Design. The MIT Press, Cambridge, MA, 2012.

17.Dourish, P., and Bell, G. Resistance is futile: reading science fiction alongside ubiquitous computing. Personal and Ubiquitous Computing, 18, 4 (2014), 769-778.

18.Dunne, A., and Raby, F. Speculative everything: design, fiction, and social dreaming. MIT Press, Cambridge, MA, 2013.

19.Dunne, A., and Raby, F. Design noir: The secret life of electronic objects. Springer Press, New York, NY, 2001.

20.Dunne, A. Hertzian tales: Electronic products, aesthetic experience, and critical design. MIT Press, Cambridge, MA, 1999.

21.Eco, U. and Robey, D. The Open Work. Harvard University Press, Cambridge, MA, 1989.

22.Eco, Umberto. The Role of the Reader: Explorations in the Semiotics of Texts. Bloomington: Indiana University Press, Bloomington, IN, 1984.

23. Gaver, W., Blythe, M., Boucher, A., Jarvis, N., Bowers, J., and Wright, P. The prayer companion: openness and specificity, materiality and spirituality. In Proc. $\mathrm{CHI}$ 2010, ACM Press (2010), 2055-2064.

24.Gaver, B., and Martin, H. Alternatives: exploring information appliances through conceptual design proposals. In Proc. CHI 2000, ACM Press (2000), 209216.

25.Hallnäs, L. and Redström, J. Slow Technology Designing for Reflection. Personal and Ubiquitous Computing, 5, 3 (2001), 201-212. 
26.Helmes, J., Taylor, A.S., Cao, X., Höök, K., Schmitt, P., and Villar, N. Rudiments 1, 2 \& 3: design speculations on autonomy. In Proc. TEI 2011, ACM Press (2011), 145-152.

27.Hertz, G. Critical Making: Manifestos. Telharmonium, Hollywood, CA, 2012.

28.Hobye, M., and Löwgren, J. Touching a stranger: Designing for engaging experience in embodied interaction. International Journal of Design, 5, 3 (2011), 31-48.

29.Kirby, D. The Future Is Now: Diegetic Prototypes and the Role of Popular Films in Generating Real-World Technological Development. Social Studies of Science 40, 1 (2010), 41-70.

30.Koskinen, I., Zimmerman, J., Binder, T., Redstrom, J., \& Wensveen, S. Design research through practice: From the lab, field, and showroom. Elsevier, Amsterdam, NL, 2011.

31.Kripke, S.A. Semantical Considerations on Modal Logic. Acta Philosophica Fennica 16, 1963 (1963), 8394.

32.Lewis, D. Truth in fiction. American Philosophical Quarterly, 15, 1 (1978), 37-46.

33.Lewis, D. K. On the plurality of worlds. Blackwell, Oxford, UK, 1986.

34.Menzel, C., Possible Worlds. In The Stanford Encyclopedia of Philosophy (Spring 2015 Edition), Zalta, E. (ed.), 2015. Retrieved June 16, 2015 from http://plato.stanford.edu/archives/spr2015/entries/possib le-worlds/

35.Murray, J. H. Hamlet on the holodeck: The future of narrative in cyberspace. Simon and Schuster, New York, NY, 1997.

36.Odom, W. T., Sellen, A. J., Banks, R., Kirk, D. S., Regan, T., Selby, M., Forlizzi, J., and Zimmerman, J. Designing for slowness, anticipation and re-visitation: a long term field study of the photobox. In Proc. CHI 2014, ACM Press (2014), 1961-1970.

37.Odom, W. T. and Wakkary, R., Intersecting with Unaware Objects. In Proc. C\&C 2015, ACM Press (2015), in press

38.Pavel, T. Possible Worlds in Literary Semantics. Journal of Aesthetics and Art Criticism 34, 2, (1975), 165-76.

39.Pierce J., and Paulos, E. Making multiple uses of the obscura $1 \mathrm{C}$ digital camera: reflecting on the design, production, packaging and distribution of a counterfunctional device. In Proc. CHI 2015, ACM Press (2014), 2103-2112.
40.Pierce, J., and Paulos, E. Counterfunctional things: exploring possibilities in designing digital limitations. In Proc. CHI 2014, ACM Press (2014), 375-384.

41.Ratto, M. Critical Making: Conceptual and Material Studies in Technology and Social Life. The Information Society: An International Journal, 27, 4, (2011), 252260.

42. Reeves, S. Envisioning ubiquitous computing. In Proc. CHI 2012, ACM Press (2012), 1573-1582.

43. Retzinger, J. P. Speculative visions and imaginary meals. Cultural Studies 22, 3-4, (2008), 369-390.

44. Ronen, R. Possible worlds in literary theory (Vol. 7). Cambridge University Press, Cambridge, UK, 1994.

45.Ryan, M.-L. The Modal Structure of Narrative Universes. Poetics Today 6, 4, (1985), 717-56.

46.Ryan, M.-L. Possible Worlds, Artificial Intelligence and Narrative Theory. University of Indiana Press, Bloomington, IN, 1991.

47.Ryan, M.-L. Possible-Worlds Theory. In Routledge Encyclopedia of Narrative Theory. Herman, D et al (eds). Routledge, London, UK, 2010, 446-450.

48. Ryan, M.-L. Possible Worlds. In the living handbook of narratology. Hühn, Peter et al. (eds.), 2012. Retrieved June 16, 2015 from http://www.lhn.unihamburg.de/article/possible-worlds

49.Sengers, P., and Gaver, B. Staying open to interpretation: engaging multiple meanings in design and evaluation. In Proc. DIS 2006, ACM Press (2006), 99-108.

50.Sengers, P., Boehner, K., David, S., and Kaye, J. J. Reflective design. In Proc. CC 2005, ACM Press (2005), ACM Press, 49-58.

51. Stolterman, E. and Wiberg, M. Concept-Driven Interaction Design Research. Human-Computer Interaction 25, 2 (2010), 95-118.

52. Sturken, M., Thomas, D., And Ball-Rokeach, S. Technological Visions: Hopes and Fears That Shape New Technologies. Temple University Press, Philadelphia, PA, 2004.

53. Tanenbaum, J., Tanenbaum, K., and Wakkary, R. Steampunk as design fiction. In Proc. CHI 2012, ACM Press (2012), 1583-1592.

54.Wakkary, R., Desjardins, A., Hauser, S. Unselfconcious Interaction: A Conceptual Construct. Interacting with Computers, (2015), (in press).

55.Wakkary, R., Desjardins, A., Hauser, S., and Maestri, L. A sustainable design fiction: Green practices. $A C M$ Transactions on Computer-Human Interaction 20, 4, (2013). Article No. 23 